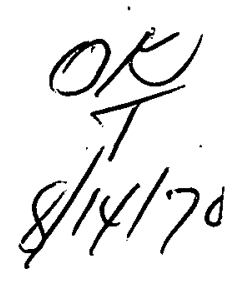

PROGRESS REPORT

for the period

June 16, 1969 - June 15, 1970

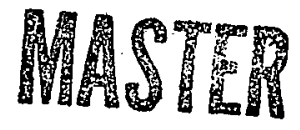

DIFFUSION STUDIES IN LIQUID METALS

$$
\text { ati. }
$$

United States Atomic Energy Commission Contract No. AT (11-1)-841

\title{
Principal Investigator
}

R. A. Swalin

Institute of Technology

University of Minnesota

June, 1970

\section{LEGAL NOTICE}

This report was prepared as an account of work sponsored by the United States Government. Neither the United States nor the United States Atomic Energy Commission, nor any of their employees, nor any of Commission, nor any of the employees, their contractors, subcontractors, or thet or assumes any makes any warranty, express or implied, or assumes any legal liability. or responsibility for the accuracy, completeness or usefulness of any information, apparatus, product or process disclosed, or represents
THIS DOCUMENT CONFIRMED AS UNCLASSIFIED DIVISION OF CLASSIFICATION BY DATE ack Hikah $8 \mid 18170$

\section{P6276}




\section{DISCLAIMER}

This report was prepared as an account of work sponsored by an agency of the United States Government. Neither the United States Government nor any agency Thereof, nor any of their employees, makes any warranty, express or implied, or assumes any legal liability or responsibility for the accuracy, completeness, or usefulness of any information, apparatus, product, or process disclosed, or represents that its use would not infringe privately owned rights. Reference herein to any specific commercial product, process, or service by trade name, trademark, manufacturer, or otherwise does not necessarily constitute or imply its endorsement, recommendation, or favoring by the United States Government or any agency thereof. The views and opinions of authors expressed herein do not necessarily state or reflect those of the United States Government or any agency thereof. 


\section{DISCLAIMER}

Portions of this document may be illegible in electronic image products. Images are produced from the best available original document. 
PROGRESS REPORT

AEC Contract No. AT(11-1)-841

\section{RESEARCH PROGRESS}

\section{A. General Comments}

During the past year, research has been performed on four interrelated aspects of the general liquids research program. The four programs are (1) thermotransport studies of liquid silver base studies containing trace amounts of solute (2) self-diffusion studies in liquid indium and liquid mercury as a function of temperature under constant volume conditions (3) radial distribution function determinations of liquid potassium and (4) electrical resistivity studies of liquid lithium. During the past year, progress was achieved in connection with the first three projects but because of experimental problems in handling lithium, resistivity measurements at constant volume were not practicable.

The undexlying philosophy of the program, in general, is to obtain data which can be used to test various models for àtomic and electronic transport processes in liquid metals. In earlier technical reports, detailed reasons were put forth for the choice of the various experimental systems chosen and types of measurements to be performed. As a consequence only a brief review of the rationale will be given here. Thermotransport studies (Soret measurement) of solute redistribution in silverbase systems in a temperature gradient are being performed for two reasons. From an applications point of view, thermal graidents often exist in situations in which liquid metals are employed. These gradients can result in segregation of solute to 
either the hot region or cold region (depending on the sign of the heat of transport). Under certain conditions embrittlement or general deterioration of container materials may occur. Suprisingly almost no thermotransport studies in liquid metals have been made. From a theoretical point of view, a quantity called the heat of transport may be obtained from thermotransport measurements. Comparison of experimentally determined heats of transport with various models of atomic transport in liquids provides a very critical test of the applicability of various models.

The self diffusion studies of liquid metals at constant volume also provides a test of various models of diffusion (See COO-841-14). Under conditions of constant pressure for example, both the free volume and average kinetic energy of the molecules increase as the temperature is increased. Under constant volume conditions, the free volume can be kept constant as the temperature is changed thus affording a better comparison with various theories of diffusion.

In similar fashion the programs which are concerned with measurements of the electrical resistivity and radial distribution functions for liquid alkali metals as a function of temperature at constant volume are designed to test models of electron transport. Theoretically speaking the alkali metals are the simplest to consider although experimentally they afford many problems. We are particularly interested in the temperature dependence of the electrical resistivity of the family of alkali metals at constant volume over a wide range of temperature as well as the changes in interference function which occurs with temperature. These measurements in concert are useful in establishing the validity of the single scattering theory approximation. 
A brief description of the progress made during the past year is presented below.

\section{B. Thermotransport Studies in Liquid Silver}

During the past year, significant progress was made. A second experimental system was constructed so as to permit two systems to be studied simultaneously. To date experimental results have been virtually completed on three systems - liquid silver containing a trace amount of radioactive gold, liquid silver containing a trace amount of radioactive antimony and liquid silver containing a trace amount of radioactive sulfur. Detailed discussion of the experiments is presented in Technical Document C00-841-19 and consequently only a brief review is presented here. Experimentally, a fused silicon capillary several inches in length which contains silver and the solute of interest is placed in a temperature gradient (typically $40^{\circ} \mathrm{C} /$ inch). The solute is initially distributed uniformly. Because of the difference in heat of transport of solute and solvent, a redistribution of solute occurs and ultimately a stationary state is reached. The sample is rapidly cooled at the termination of the experiment and the solute concentration is measured as a function of distance. In turn, the temperature is a function of distance and a graph is obtained of the logarithm of solute concentration versus the reciprocal of absolute temperature. Gold was chosen as one solute inasmuch as it behaves almost ideally in liquid silver and thus provides a baseline for comparison. Antimony was chosen because we had earlier made isothermal diffusion studies of the series indium, tin and antimony in silver and thus have considerable experimental experience and data. Sulfur was chosen because it appears to diffuse very rapidly in liquid silver and was considexed to represent an extreme case. 
Upon application of the thermodynamics of irreversible processes, the following equation is obtained for the solute redistribution in a temperature gradient at the stationary state

$$
\ln \frac{x_{2}^{C}}{x_{2}^{H}}=\frac{1}{R}\left(Q_{2}^{*}-Q_{1}^{*} \frac{\bar{V}_{2}}{\bar{v}_{1}}\right)\left(\frac{1}{T_{C}}-\frac{1}{T_{H}}\right)
$$

In this equation $X_{2}$ is the atom fraction of solute. The notations $C$ and $H$ represent cold and hot end respectively. $Q_{2}^{*}-Q_{1}^{*}$ represent the heat of transport of solute and solute respectively and $\bar{v}_{2}$ and $\bar{v}_{1}$ represent partial molar volumes of solute and solvent respectively. The above equation is applicable as it stands for small solute concentrations. From the equation, we see that a plot of $\ln X_{2}$ versus $1 / T$ along the sample yields a curve which has a slope equal to

$$
\frac{I}{R}\left(Q_{2}^{*}-Q_{1}^{*} \varnothing\right)
$$

where $\emptyset$ is equal to $\bar{V}_{2} / \bar{v}_{1}$.

Typical data for gold, antimony and sulfur are shown in Figs. 1, 2 and 3 and values of $\left(Q_{2}^{*}-Q_{1}^{*} \bar{V}_{2} / \bar{V}_{1}\right)$ are obtained from the slopes.

One can observe from the data that the segregation is surprisingly large. For . example, in the case of antimony, the concentration of solute is 1.25 as high at the hot end as compared with the cold end (Fig. 2). The effect for sulfur is much larger and the solute ratio at hot and cold end respectively is about a factor of 10. (Fig. 3). The experimentally determined values of $\left(Q_{2}^{*}-Q_{1}^{*} \emptyset\right)$ are shown in the following table: 
Solute in Ag

$\mathrm{Au}$

$\mathrm{Sb}$

S
$\left(Q_{2}^{*}-Q_{1}^{*} \emptyset\right)(\mathrm{cal} / \mathrm{g}$-atom $)$

3100

- 8300

$-76,800$

The solutes antimony and sulfur migrate preferentially to the hot end whereas gold migrates to the cold end. A detailed atomistic interpretation has not yet been made but it is interesting to note that there is a general relation between the magnitude and sign of $\left(Q_{2}^{*}-Q_{1}^{*} \emptyset\right)$ and the difference in diffusion coefficient between solute and solvent. Gold, for example, in the temperature range investigated has a diffusion coefficient in silver which is equal to about 0.90 of that for silver in silver. Antimony in silver diffuses about 1.5 times as fast as silver and sulfur diffuses about 2. 5 times as fast.

C. Self-Diffusion in Liquid Indium and Liquid Mercury at Constant Pressure and Constant Volume

Much of the year was devoted to a refinement of the experimental pressure temperature curves for the constant volume condition. The curve as established for indium is shown in Fig. 4. In the case of mercury, it was decided that the range of temperature measurement could be somewhat expanded if data could be obtained at temperatures below room temperature inasmuch as $\mathrm{dP} / \mathrm{dT}$ is less at low temperatures than at high temperatures. As a consequence, apparatus has been constructed for the 
purpose of determining the pressure - temperature curve as well as diffusion properties down to the freezing point of mercury. A dry ice-acetone bath is employed for the purpose of achieving low temperatures for diffusion.

Prior to measuring the diffusion coefficient under the constant volume condition, measurements are made as a function of temperature at constant pressure in order to establish the technique and to check the accuracy of existing data in the literature. It is necessary to know accurately the temperature dependence of the self-diffusivity at constant pressure since these are necessary as a base for comparison. Measurements for indium have been completed and these are shown in Fig. 5 . In the case of mercury measurements of the self diffusivity as a function of temperature at constant pressure are underway. Data are being obtained from the melting point of mercury up to above room temperature.

In the case of diffusion measurements at constant volume, work has been initiated on indium and is in the early stage of study.

D. Radial Distribution Function Measurements (RDF) for Liquid Potassium at Constant Volume

Most of the year was spent in improving the equipment and in determining more precisely the backgxound scattering correction. For example, the X-ray intensity is somewhat sensitive to the rate of cooling water flow. In order to minimize fluctuations in intensity which resulted from changes in cooling water flow, the design of the system was altered so as to maintinin a steady flow over a period as long as 10 days. 
In our previous work on sodium which is presently being prepared for publication, it was assumed that the contribution from background scattering could be assumed to be independent of temperature. By improving the design of equipment, we are now able to align the sample more precisely than before in the X-ray beam and as a result are able to reduce significantly some of the corrections needed earlier. We have some evidence now that, for $2 \theta$ values below $20^{\circ}$, the background scattering might depend upon temperature. In order to obtain useful data at low angles, the appropriate background corrections must be made.

At the present time, the nature of the background correction is being analysed and now X-ray diffraction data are being obtained for potassium.

In the last proposal we discussed tentative plans for initiation of a neutron diffraction program. Inquiry to various laboratories which have suitable experimental facilities did not result in location of facilities that would be available for a time sufficient for our proposed use so this aspect of the program is postponed.

E. Electrical Resistivity Measurements for Liquid Lithium

As part of our general program of electrical resistivity measurements, it is desirable to have data for lithium inasmuch as there is some evidence that this material behaves anomalously as compared with the other alkali metals. Attemptsto date to obtain suitable data have met with problems which is apparently caused by an interaction between liquid lithium and invar which is used as the cell material. As a consequence, a different experimental arrangement is needed for future measurements. 


\section{BIBLIOGRAPHY}

Since the last progress report (COO-841-18) the following technical reports have been either newly issued or published in technical journals.

C00-841-17: S. Y. Lien and J. M. Sivertsen.

The Resistivity versus Temperature at Constant Volume of Liquid Na, $\mathrm{K}$ and Rb. Philosophical Magazine, Vol. 20, pp. 759-762 (1969).

(Reprints enclosed).

COO-841-19: B. H. Bhat and R. A. Swalin, Thermotransport of Solutes in Liquid Silver. 


\section{List of Figures}

1. Log concentration of gold versus the reciprocal of absolute temperature.

2. Log concentration of antimony versus the reciprocal of absolute temperature.

3. Log concentration of sulfur versus the reciprocal of absolute temperature.

4. Calibration curve of liquid indium at constant volume.

5. Diffusion of indium at constant pressure. 


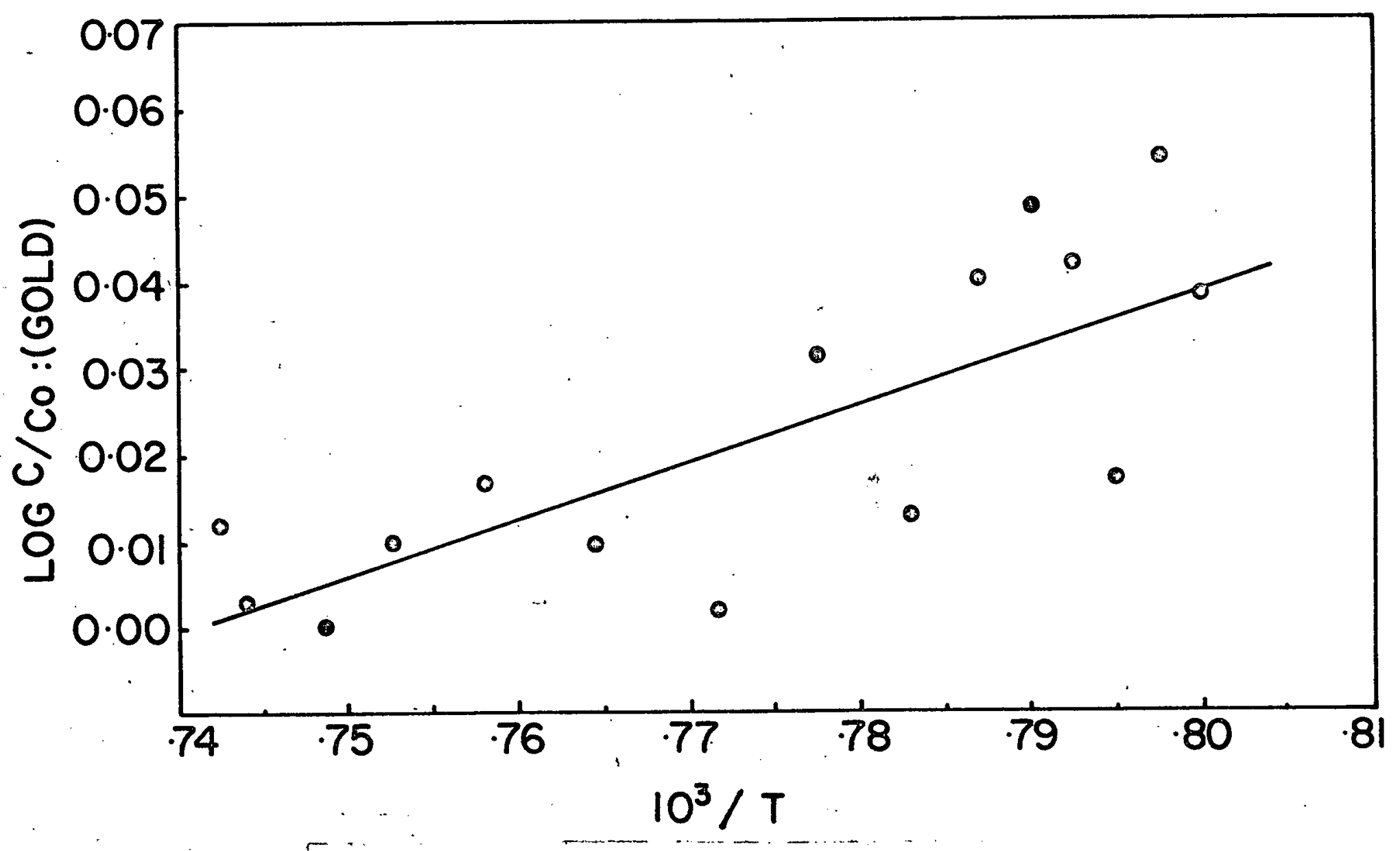

Fig. 1. Log concentration of gold versus the reciprocal of absolute temperature. 


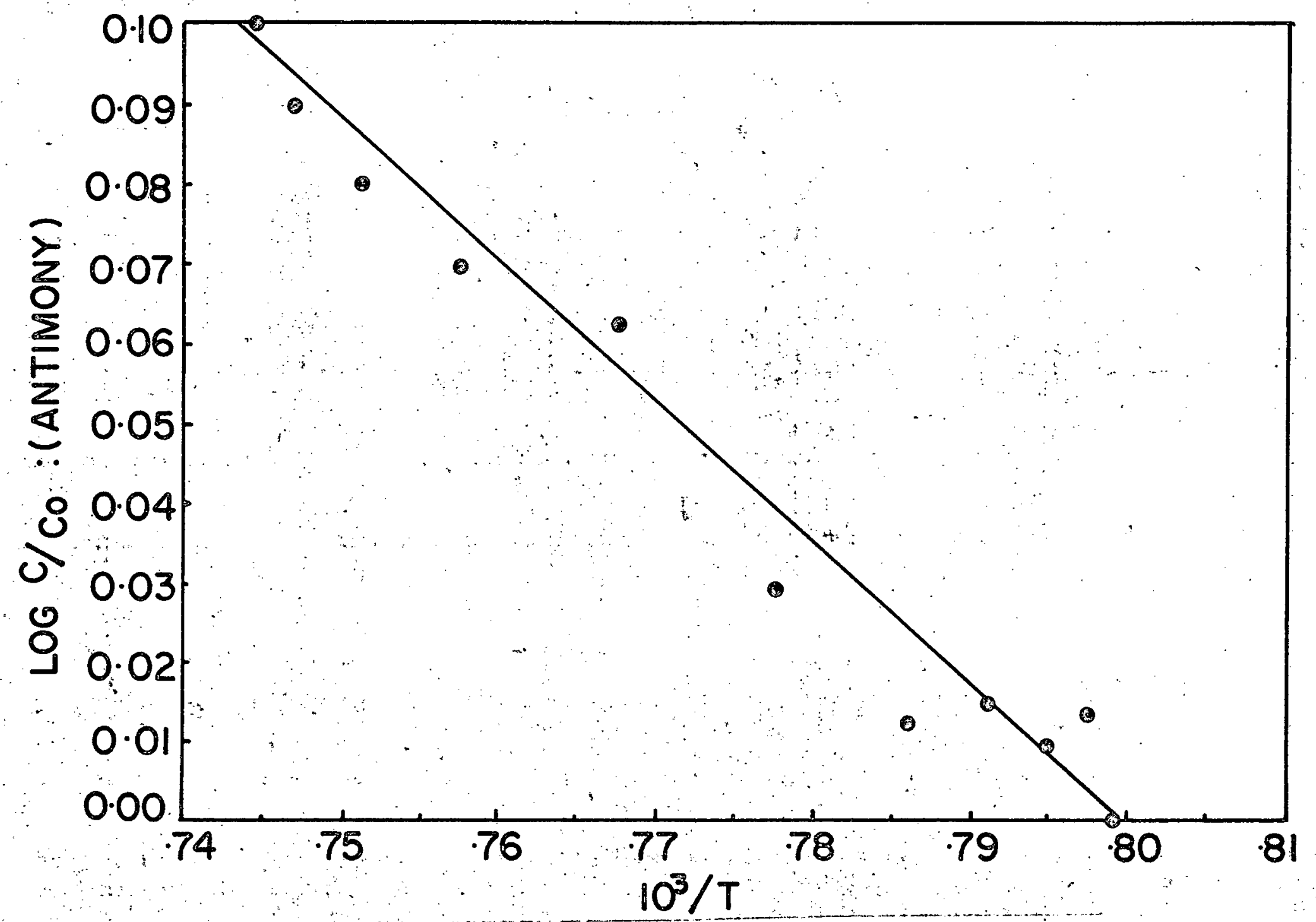

Fig. 2. Log concentration of antimony versus the reciprocal of absolute temperature. 


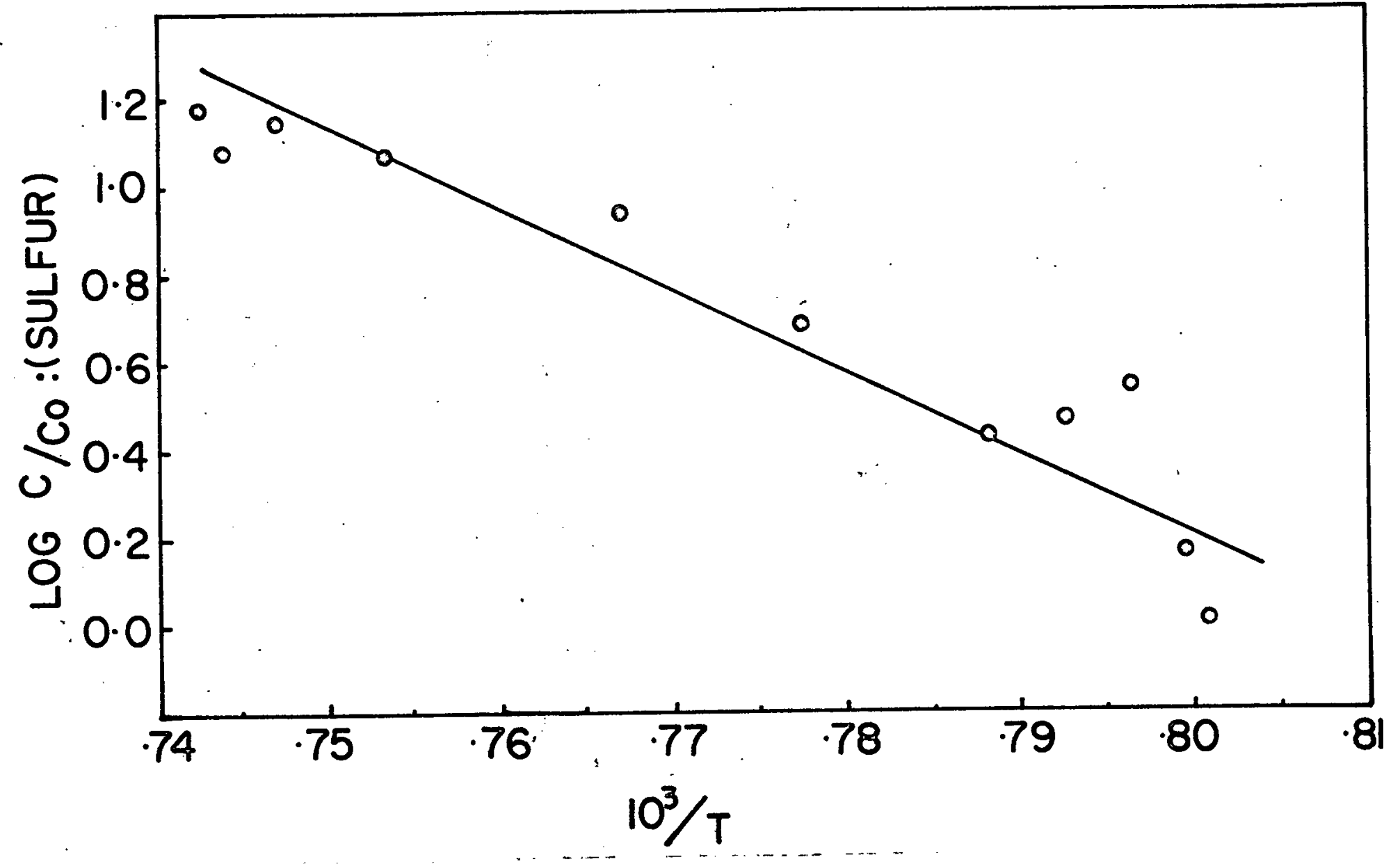

Fig. 3. Log concentration of sulfur versus the reciprocal of absolute temperature. 


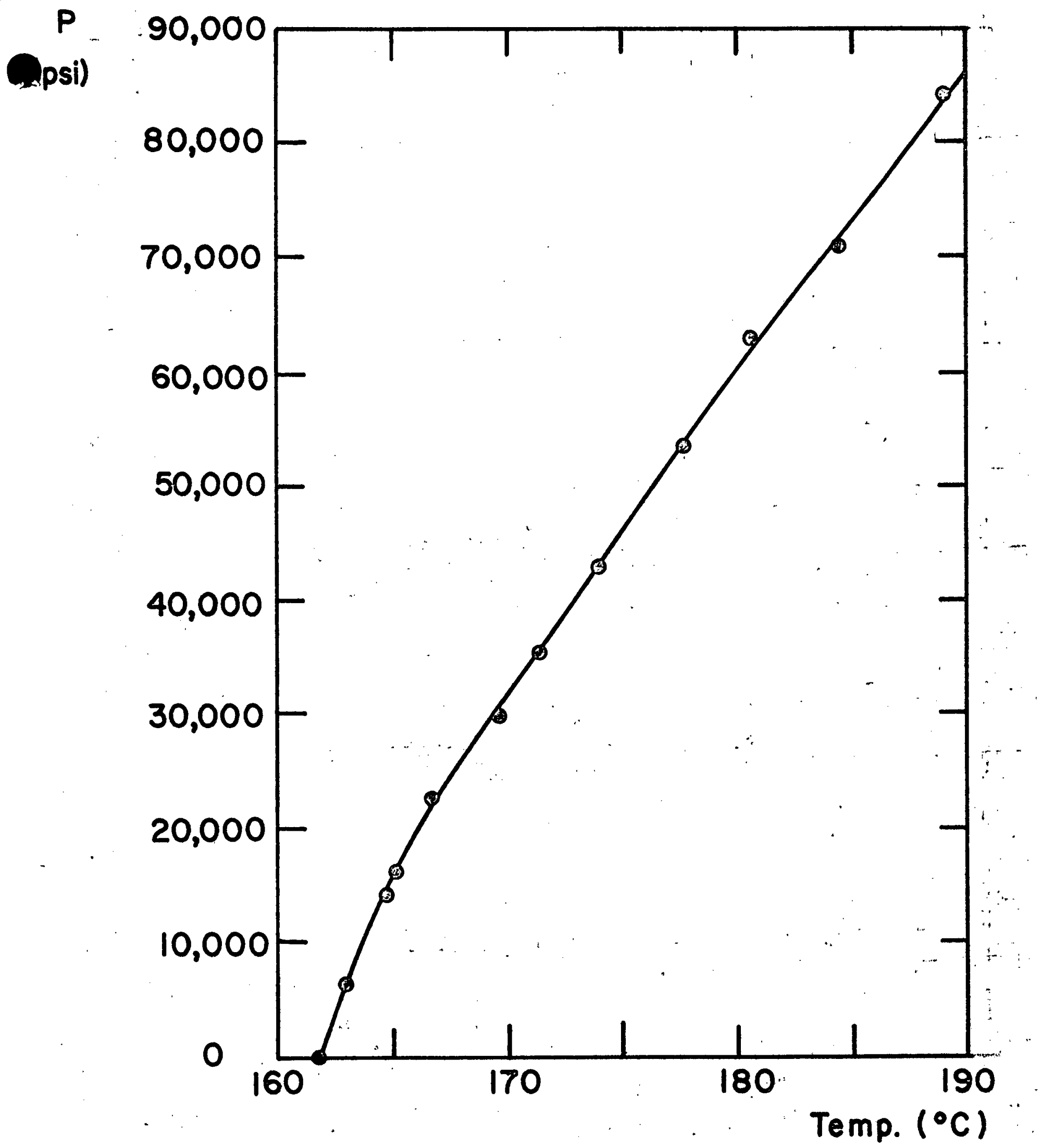

FIG. 4. Calibrotion curve of liquid Indium at constant volume. 


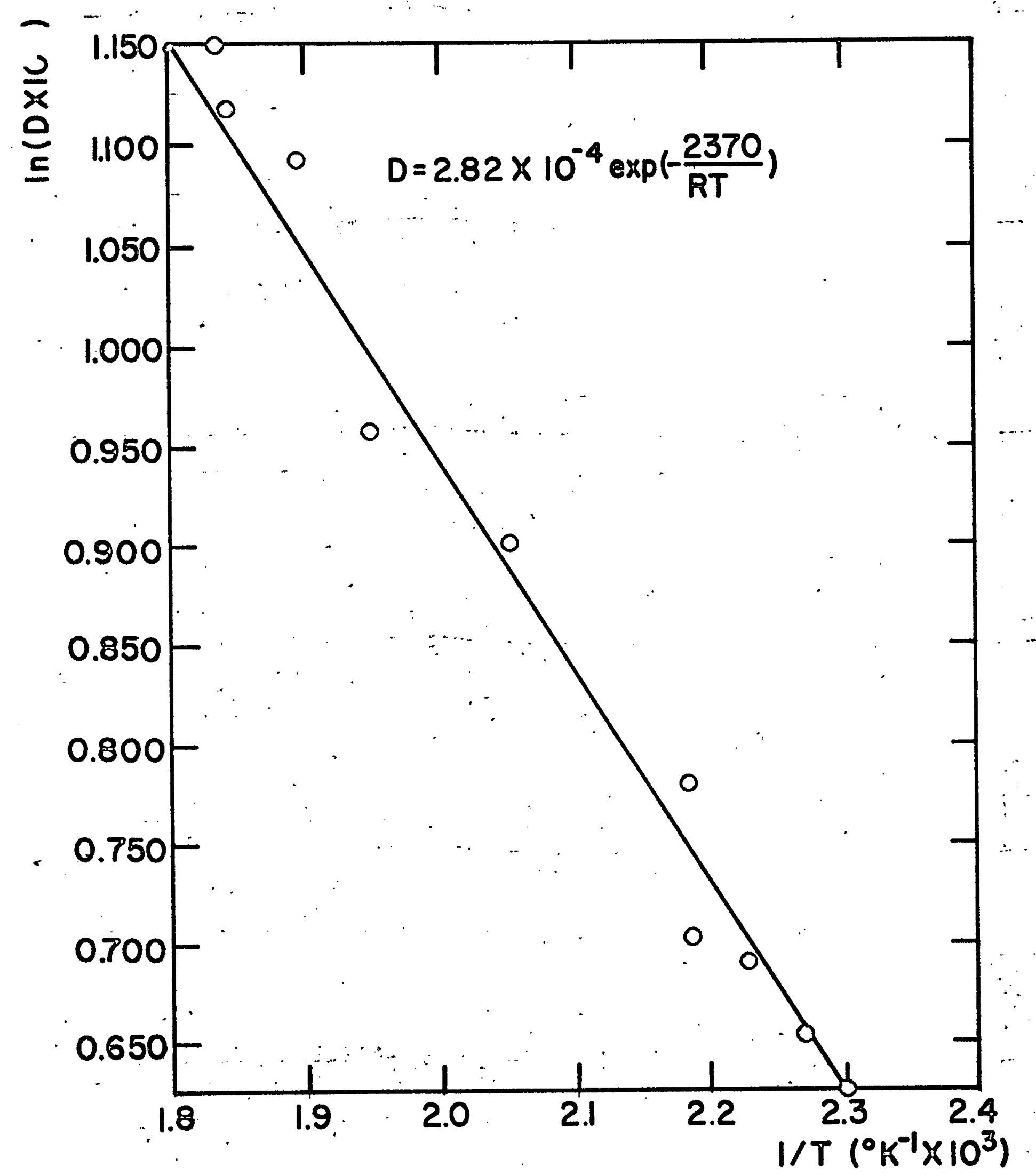

FIG.5. Diffusion of Indium af consiant pressure 